\title{
The use of an online three-dimensional model improves performance in ultrasound scanning of the spine: a randomized trial
}

\author{
L'utilisation d'un modèle tridimensionnel en ligne améliore la \\ performance d'interprétation de l'échogramme de la colonne \\ vertébrale: une étude randomisée
}

\author{
Ahtsham U. Niazi, MD • Gordon Tait, PhD • \\ Jose C. A. Carvalho, MD, PhD • Vincent W. Chan, MD
}

Received: 17 September 2012/ Accepted: 29 January 2013/Published online: 12 February 2013

(C) Canadian Anesthesiologists' Society 2013

\begin{abstract}
Purpose The use of ultrasound for neuraxial blockade is a new application of technology that is rapidly becoming accepted as a standard of care. This new skill has shown to improve success, but it is a challenge to teach. To assist with teaching the use of ultrasound in regional anesthesia of the lumbar spine, we have developed an interactive educational model (http://pie.med.utoronto.ca/vspine or http://www.usra.ca/vspine.php). In this study, we aimed to
\end{abstract}

Presentation: This study has been presented as a poster at the Canadian Anesthesiologists' Society Annual Meeting in Quebec, June 2012.

Author contributions Ahtsham U. Niazi is the principal author who conceived the study design, obtained the subjects' consent, and acquired the data. Gordon Tait is a co-principal author responsible for the study design and data analysis. Ahtsham U. Niazi and Gordon Tait were responsible for the conduct of the study and for writing the manuscript. Gordon Tait and Jose C.A. Carvalho are co-principal authors responsible for revising the manuscript. Vincent $W$. Chan is the senior author responsible for approving the final draft of the manuscript for publication.

A. U. Niazi, MD $(\bowtie) \cdot$ V. W. Chan, MD

Department of Anesthesia and Pain Management, Toronto

Western Hospital, University Health Network, University of

Toronto, 399 Bathurst St., Toronto, ON M5T 2S8, Canada

e-mail: ahtsham.niazi@uhn.on.ca

G. Tait, $\mathrm{PhD}$

Department of Anesthesia, Toronto General Hospital, University

Health Network, University of Toronto, Toronto, ON, Canada

J. C. A. Carvalho, MD, $\mathrm{PhD}$

Department of Anesthesia, Mount Sinai Hospital, University of

Toronto, Toronto, ON, Canada determine whether use of this model for a two-week period would improve the performance of novice operators in determining defined landmarks during real-time ultrasound imaging of the lumbar spine.

Methods We evaluated the educational benefit of the ultrasound module by randomly assigning 16 postgraduate firstyear (PGY1) anesthesia residents to either a control group with password-protected access to only the lumbar anatomy module or to an intervention group with access to the complete module. All residents had access to the module for two weeks following a full-day workshop that is part of the university teaching program which consists of a didactic lecture on ultrasoundfacilitated neuraxial anesthesia, mentored teaching on cadaveric spine dissections, and hands-on ultrasound scanning of live models. At the end of the two weeks, the performance of the residents was evaluated using a 12-item task-specific checklist while carrying out a scout scan on a live model.

Results The control group had a median score of 5.5 (25 $5^{\text {th }}$ percentile: $4,75^{\text {th }}$ percentile: 18$)$, while the intervention group had a median score of $11.5\left(25^{\text {th }}\right.$ percentile: $8,75^{\text {th }}$ percentile: 12) in the task-specific checklist, with a significant difference of 6 (confidence interval 1.5 to 10.5) between groups $(P=0.021)$.

Conclusion Our results show superior performance by the residents who had access to both components of the module, indicating that access to the interactive ultrasound spine module improves knowledge and skills prior to clinical care.

\section{Résumé}

Objectif L'utilisation de l'échographie pour les blocs neuraxiaux est une nouvelle application de cette 
technologie dont l'utilisation devient rapidement acceptée comme norme de soins. Il a été démontré que cette nouvelle compétence améliorait les chances de réussite du bloc; toutefois, son enseignement est un défi. Afin d'aider à l'enseignement de l'échographie en anesthésie régionale de la colonne lombaire, nous avons mis au point un modele pédagogique interactif (http://pie.med.utoronto.ca/vspine ou http://www.usra.ca/vspine.php). Dans cette étude, notre objectif était de déterminer si l'utilisation de ce modèle au cours d'une période de deux semaines améliorerait la performance de nouveaux opérateurs à placer des points de repères précis pendant une échographie en temps réel de la colonne lombaire.

Méthode Nous avons évalué les avantages pédagogiques du module d'échographie en attribuant aléatoirement 16 résidents en anesthésie de première année (PGY1) à un groupe témoin ayant un accès protégé par mot de passe au module d'anatomie lombaire uniquement ou à un groupe intervention ayant accès au module complet. Tous les résidents ont eu accès au module pendant deux semaines après un atelier d'un jour faisant partie du programme d'enseignement de l'université. Cet atelier comprenait une conférence didactique sur l'anesthésie neuraxiale facilitée par l'échographie, de l'enseignement encadré sur des dissections de colonne sur des cadavres, et des cours pratiques d'échographie sur des modèles vivants. À la fin des deux semaines, la performance des résidents a été évaluée à l'aide d'une liste de contrôle spécifique de 12 éléments pendant une échographie de dépistage sur un modèle vivant.

Résultats Le score médian du groupe témoin était de 5,5 (25 percentile: $4,75^{e}$ percentile: 18$)$, alors que le score $d u$ groupe intervention était de $11,5\left(25^{e}\right.$ percentile: $8,75^{e}$ percentile: 12) sur la liste de contrôle spécifique à la tâche, avec une différence significative de 6 (intervalle de confiance 1,5 à 10,5) entre les groupes $(P=0,021)$.

Conclusion Nos résultats démontrent une meilleure performance chez les résidents ayant eu accès aux deux volets du module, ce qui indique que l'accès au module interactif d'échographie de la colonne ameliore les connaissances et les compétences avant les stages cliniques.

The use of ultrasound for neuraxial blockade is a new application of technology that is rapidly becoming accepted as a standard of care. Research supports both an improvement in success and a reduction in attempts while applying the technique. ${ }^{1,2}$ In January 2008, the National Institute for Health and Clinical Excellence (NICE) in the United Kingdom published guidelines ${ }^{3}$ suggesting that ultrasound could be used both as a pre-procedural assessment tool and for real-time needle insertions. Preprocedural scanning involves scanning the patient's lumbar spine to locate the intervertebral spaces, identify the midline, and determine the depth to the epidural space.

The teaching of spinal ultrasound assessment has been shown to be challenging, and the reasons for that difficulty are yet to be identified. ${ }^{4}$ There are two aspects to the skills involved in conducting a pre-puncture scan: 1) the cognitive skills of interpreting the ultrasound images and identifying the anatomic structures seen in the images and 2) the manual skills of manipulating the ultrasound probe to achieve clear images of the structures and of marking the skin to indicate the intervertebral spaces and the midline of the spine to guide needle insertion.

To help with the acquisition of these skills, we have developed a novel online three-dimensional (3-D) model of the spine and linked it with ultrasound images to create an interactive teaching aid for medical educators and trainees learning the use of ultrasound to facilitate neuraxial blocks (http://pie.med.utoronto.ca/vspine or http://www.usra.ca/ vspine.php).

Our study aimed to determine whether the use of this model for a two-week period would improve the performance of novice operators in determining defined landmarks during real-time ultrasound imaging of the lumbar spine.

\section{Methods}

The study was designed as a randomized controlled singleblinded study. After obtaining University Health Network Research Ethics Board approval in March 2011, 16 firstyear anesthesia residents consented to participate in the study (Fig. 1). Exclusion criteria included previous experience with spinal ultrasound and declining to participate in the study.

Computer-generated numbers were used by one of the authors (G.T.) to randomize the residents into two groups, i.e., the study group and the control group. Eight digit random number passwords were generated to allow access to the complete site (study group) or the partial site (control group). These passwords were then secured in sealed envelopes by the same author and distributed to the residents. Each resident was provided with instructions for the study after attending a spinal ultrasound training workshop. This one-day workshop is part of the university teaching program and consists of a 45-min didactic lecture on ultrasound-facilitated neuraxial anesthesia, a 45-min session of mentored teaching on cadaveric spine dissections, and a two-hour hands-on session on ultrasound scanning of live models. 
Fig. 1 Study flow diagram. The complete class of postgraduate first-year anesthesia residents was eligible for recruitment. One student declined to participate and 16 anesthesia residents were recruited and randomized to equal groups. All recruited residents completed the study

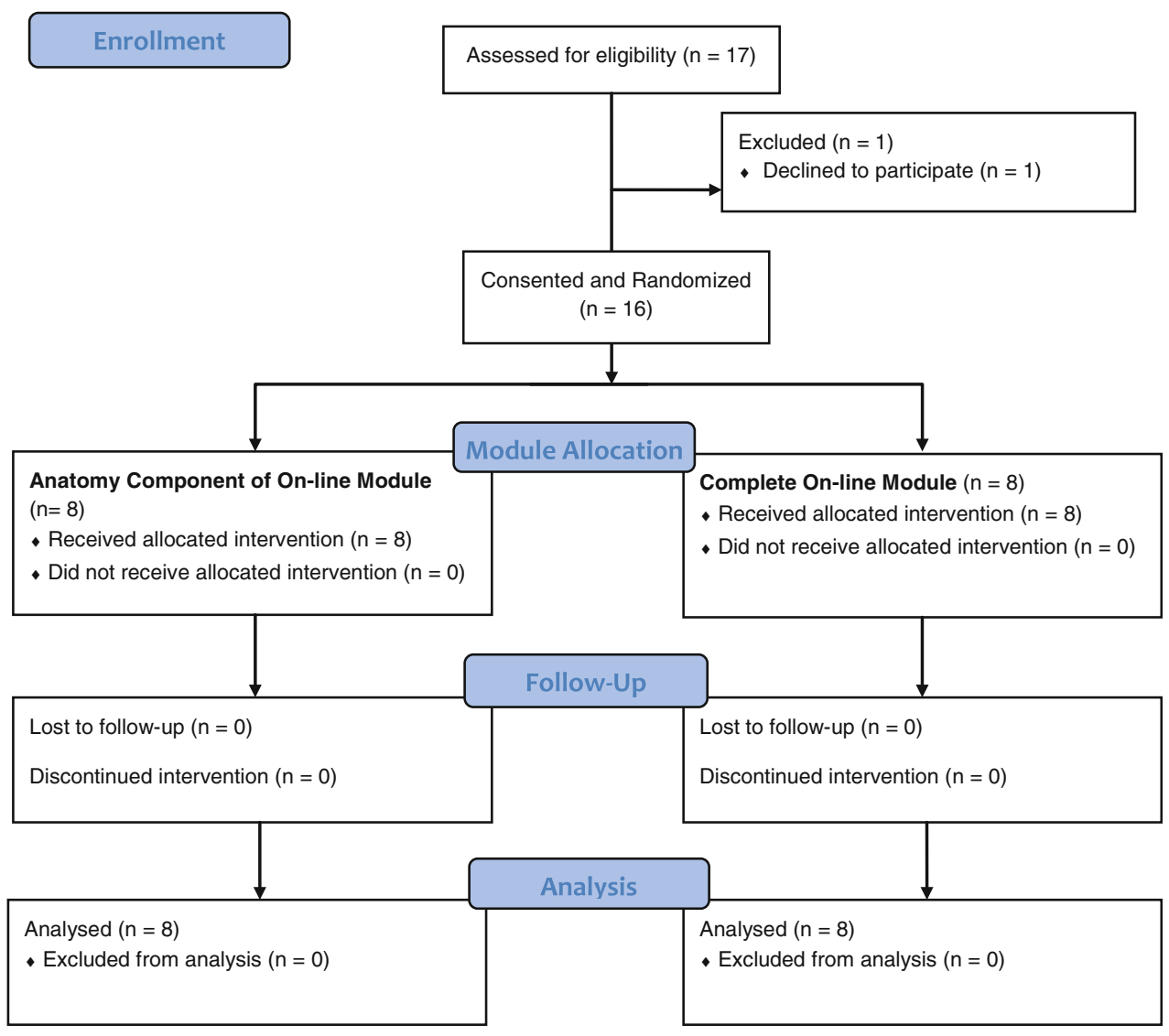

Both groups had access to the Virtual Spine Web site, an online 3D teaching resource consisting of three modules: 1) spinal anatomy, 2) spinal sonoanatomy, and 3) a simulation of a pre-procedural "scout" scan of the lumbar spine that provides a simulation of the process of adjusting the probe to obtain the optimal ultrasound views. The study group was provided password-protected access to all three modules for two weeks following the workshop, while the control group was provided password-protected access to only the spinal anatomy module. The Virtual Spine Web site was password-protected during the two-week period of the study to prevent contamination from access to the site by the control group.

When the subjects logged on to the Web site, all their mouse clicks were tracked to allow tracking of the time the subjects spent on the Web site, defined as the time from the first to the last click of the mouse. An interval of time longer than 15 min between mouse clicks was subtracted from the time on the site. This tracking also provided information on the access to each feature of the module (e.g., the number of times the residents switched between the transverse and the longitudinal view and the simulation of the scout scan).

At the end of two weeks, an independent investigator blinded to the study group assessed both groups on their performance of a pre-puncture scan on a live model. The models had a prominent easily palpable normal spine and typical sonoanatomy at each lumbar space. An ultrasound expert who was not involved in the academic assessment of the residents carried out the measurement of each subject's performance. Subjects' random number passwords were used as the subject ID for recording the score, providing anonymity of the results from the investigator. This also allowed each subject's score to be related to the tracking of the subject's access to the Web site. Both groups were told that they would have free access to the online modules after their assessments were completed at the end of the study. Study participants received modest financial compensation for their time. While conducting the scan, the study participants were assessed using a task-specific checklist (Table 1) and the Generic Technical Skills Global Rating Scale (Table 2). The scores on the Global Rating Scale ranged from $0-40$. The items in the task-specific checklist were directly related to the content of the online learning module that was provided to the study group, so it was judged to be the most sensitive to show a benefit from use of the learning module. The task-specific checklist measured the success or failure in the ability to identify key landmarks on the lumbar spine during the sagittal paramedian and transverse scanning of the spine. Study participants were asked to locate the sacrum and to identify each lumbar intervertebral space in the sagittal view by 
marking each interspace on a plastic film that was applied over the model's skin (Fig. 2). They were asked to identify the L3-L4 interspace in the transverse view, to point out the ligamentum flavum-dura mater unit and the vertebral body, and to measure the depth of the ligamentum flavum-dura mater unit from the skin. One point was given for each correctly identified structure and zero points were given for an incorrect answer. At the L3-L4 interspace, subjects were also asked to mark the midline and the centre of the interspace and to define the needle insertion point on the plastic film applied over the model's skin. A blinded trained research coordinator recorded the subjects' scores. Each subject was allowed a maximum of $15 \mathrm{~min}$ to complete the scan, and then scanning was discontinued. The primary outcome of the study was the ability of the participants to identify key anatomical landmarks of the lumbar spine as defined by the total score of the 12 items listed on the checklist in Table 1. The scores were expressed as the number of correct items ranging from $0-12$. A secondary outcome was the assessment of the study participant on the Generic Technical Skills Global Rating Scale (Table 2). ${ }^{5}$

\section{Statistical analysis}

Statistical analysis was carried out using SPSS ${ }^{\circledR} 17.0$ for Windows (SPSS Inc., Chicago, IL, USA). The participants' scores on the checklist and on the Global Rating Scale were summarized as median values and the interquartile range. Statistical significance was established at a $P$ value $<0.05$. The Mann-Whitney U test was used to compare the differences between the scores of the study group and the

Table 1 Task-specific Checklist

\begin{tabular}{|c|c|c|c|}
\hline & & US Plane & Correct \\
\hline 1 & Sacrum & Longitudinal & \\
\hline 2 & L5-S1 & Longitudinal & \\
\hline 3 & L4-L5 & Longitudinal & \\
\hline 4 & L3-L4 & Longitudinal & \\
\hline 5 & L2-L3 & Longitudinal & \\
\hline 6 & L1-L2 & Longitudinal & \\
\hline 7 & Midline & Transverse & \\
\hline 8 & $\begin{array}{l}\text { Ligamentum Flavum/Dura } \\
\text { Mater }\end{array}$ & Transverse & \\
\hline 9 & $\begin{array}{l}\text { Posterior Longitudinal } \\
\text { Ligament (PLL)/Vertebral } \\
\text { Body }\end{array}$ & Transverse & \\
\hline 10 & Facet Joints & Transverse & \\
\hline 11 & Insertion Point at L3-L4 & Transverse & \\
\hline 12 & $\begin{array}{l}\text { Depth to Ligament Flavum at } \\
\text { L3-L4 }\end{array}$ & Transverse & \\
\hline
\end{tabular}

$\mathrm{L}=$ lumbar vertebra; $\mathrm{S}=$ sacral vertebra; $\mathrm{US}=$ ultrasound scores of the control group on the task-specific checklist and on the Generic Technical Skills Global Rating Scale. All tests were two-sided.

The sample size was calculated by the standard method of selecting a difference between the groups that would be considered clinically significant and then based on a reasonable estimate of the variance of the sample size that would be required to detect that difference. There were no previous data on which to base the estimate of variance, thus a reasonable estimate was used. In fact, the study sample was virtually the whole PGY1 class of 17 students, as everyone volunteered except one student who was out of town during the study. A Student's $t$ test was used to calculate the sample size necessary to detect a difference between the average scores on the task-specific checklist of the two groups. The scores for individuals can range from $0-12$. For a difference of 3.6 between the groups and a standard deviation of 2.4, the sample size required in each group was 7 with a power of 0.80 and a two-tailed alpha of 0.05 .

\section{Results}

Seventeen first-year anesthesia residents were eligible for our study. All residents were approached, but one resident had prior plans for the weekend of the study and therefore was excluded. Sixteen first-year anesthesia residents completed the study. All residents were tested two weeks after attending the one-day workshop. The study group logged on to our online interactive 3-D spine model an average of 3.9 times and spent an average of 42 (27) min reviewing the content. The control group logged on an average of 1.4 times and spent an average of 13 (5) min reviewing the content. In the assessment of the scores using the Mann-Whitney U test, the median score for the study group was $11.5\left(25^{\text {th }}\right.$ percentile: $8,75^{\text {th }}$ percentile: 12 ), and the median score for the control group was $5.5\left(25^{\text {th }}\right.$ percentile: $4,75^{\text {th }}$ percentile: 8$)$, with a difference of 6 between the groups. This result was statistically significant $(P=0.021)$. As a secondary outcome, the performance of the two groups on the Generic Technical Skills Global Rating Scale was also compared using the Mann-Whitney U test. The median score was 29.5 ( $25^{\text {th }}$ percentile: $26.5,75^{\text {th }}$ percentile: 35.5 ) for the study group and $22\left(25^{\text {th }}\right.$ percentile: $18,75^{\text {th }}$ percentile: 27$)$ for the control group. The difference of 7.5 between the two groups did not achieve statistical significance $(P=0.054)$.

\section{Discussion}

Our results show that the residents who had access to both components of the module demonstrated superior 


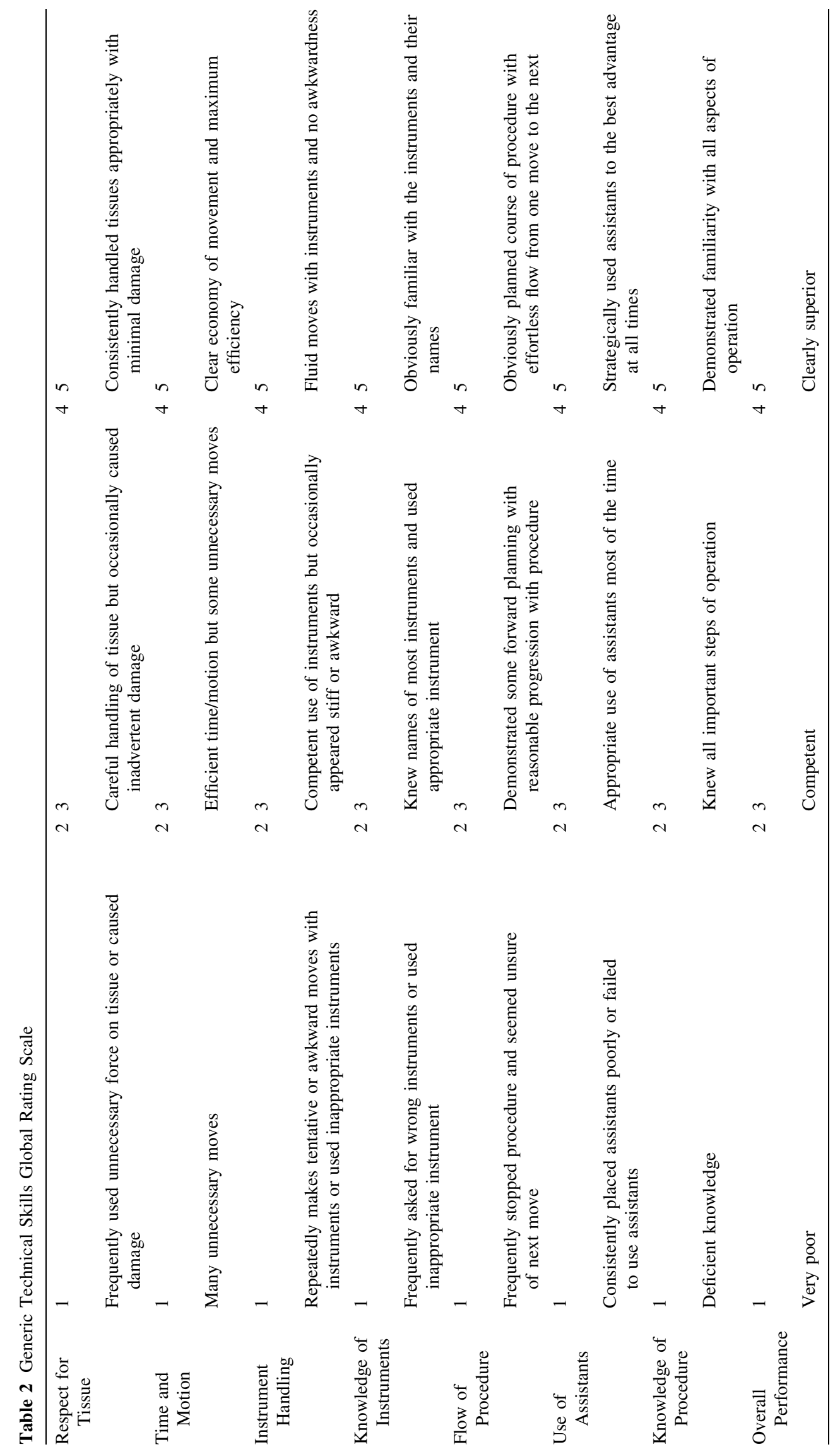




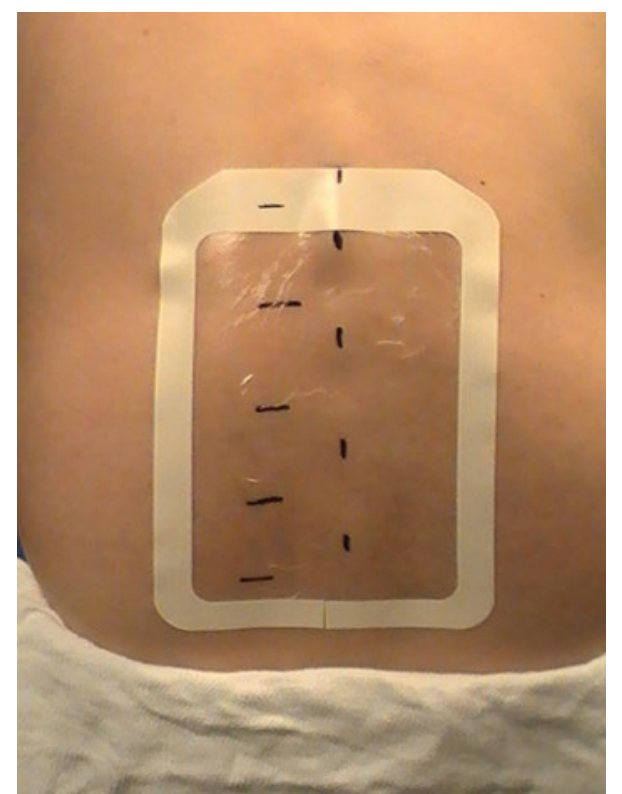

Fig. 2 Model with markings after a resident evaluated the midline and the lumbar interspaces

performance in identifying key landmarks, indicating that access to the interactive 3-D spine model module improves knowledge and skills in conducting a pre-puncture ultrasound scan prior to clinical care. The fact that the median scores on the task-specific checklist were twice as high in the study group than in the control group indicates a clinically important benefit of the intervention (effect size $=$ difference/standard deviation $=2.08$ ).

The application of ultrasound technology provides some benefits to visualization of landmarks that are difficult to feel with surface anatomy in the presence of obesity or spinal abnormalities. ${ }^{6,7}$ It also facilitates identifying the correct lumbar interspaces, as it has been shown repeatedly that palpation of the spine for identification of a particular lumbar vertebra is inaccurate even with experienced practitioners. ${ }^{8-10}$ Nevertheless, teaching the use of ultrasound in guiding neuraxial blockade can be challenging, as new knowledge must be learned and new skills must be acquired.

Margarido et al. have found that developing competence in performing a pre-puncture scan is not a simple process. ${ }^{4}$ Participants in their study were provided reading material and an educational video on ultrasound-facilitated spinals and epidurals that they were required to review prior to a 45 -min lecture. This was followed by a 15 -min demonstration on a live model and a 30-min hands-on workshop in a small group setting. Despite this comprehensive training program, the results were disappointing when the participants were tested on a live model one to two weeks later. None of the participants were able to achieve competence in identifying the correct insertion point or the depth to the ligamentum flavum. While some of the failure may be ascribed to the inability to master the demanding manual skill, some may also be due to failure to retain the cognitive knowledge. The advantage of an online virtual reality model is its availability to the learner. Our study group could access our module at any time. Although they had access to the module for two weeks, most of our residents spent the greatest amount of online time close to the assessment day; therefore, the study group had "justin-time" access to the interactive teaching module and did not have to rely on knowledge retention for their performance. Just-in-time access to learning material is analogous to the concept of "just-in-time" inventory control in manufacturing, where the materials are provided just in time for the manufacturing process, eliminating the need for a large inventory. ${ }^{11}$ "Just-in-time" learning has been characterized as "anywhere, anytime, anyhow learning that is just enough, just for me, and just in time". ${ }^{12}$ Online learning material that is accessible just before it is needed reduces the requirement for retention needed when learning takes place a long time before the relevant task is required. The learning material is far more likely to be retained once it is used in accomplishing the task.

The control group spent less time logged on compared with the study group (average 13 vs $42 \mathrm{~min}$, respectively). This difference is doubtless because the ultrasound teaching module was larger than the spinal anatomy component; it contained more text concerning sonoanatomy, and it also included the pre-puncture scan, which could take some time if performed properly. It is also possible that many of the residents in the control group thought they already knew the anatomy of the spine and required no further knowledge.

The use of virtual computer-based simulation to improve procedural skills has been shown to be beneficial both in the specialty of surgery and in anesthesia. Park et al. ${ }^{13}$ showed that practicing for two to three hours on a computer-based colonoscopy simulator was effective in transferring skills to live models. In their study looking at the use of virtual simulation in teaching fibreoptic intubation, Boet et al. ${ }^{14}$ showed that self-training on the virtual fibreoptic intubation software improved the acquisition of fibreoptic intubation skills in 42 undergraduate medical students. Nevertheless, both of these studies involved simulators with a physical component that allowed practice of manual skills. Conversely, our model provided only the cognitive knowledge of using ultrasound to identify the key spinal landmarks and did not provide practice with the manual skill of performing a spinal ultrasound. Despite this, exposure to the interactive learning module improved the ability to perform a pre-puncture scan correctly. In our view, our virtual spine model acts as a part task trainer and enhances the learning of pre-puncture scanning. Part task training breaks down one task into many parts, and this 
focused training leads to more rapid development of automatic skills that otherwise may not be achieved in the context of the whole task. ${ }^{15}$

Our study has several limitations. First, the students were assessed on models based on normal anatomy where pre-puncture scans were relatively easy to perform and the key landmarks were easily identifiable. The scans can be more difficult and the landmarks harder to identify when patients have an abnormal spine or a higher body mass index. Second, our study looked at only one component of the ultrasound-guided neuraxial technique, that is, the prepuncture scan. We do not know whether experience with this online interactive module would increase the first-attempt success rate of performing spinal/epidural anesthesia.

In the future, our trainees will be provided with access to the Virtual Spine module prior to participating in the spinal ultrasound workshop to prepare them for their training in ultrasound-guided neuraxial anesthesia. Once learners are familiar with the landmarks and probe manipulations, it should be easier for them to identify the appropriate landmarks on patients. The Virtual Spine module is now freely available online at http://pie.med.utoronto.ca/spine or at http://www.usra.ca/vspine.php, and it is being used by about 1,300 trainees and medical educators per month from around the world.

In conclusion, the Virtual Spine 3-D module may assist in providing users with the knowledge and skill required to perform a pre-puncture scan of the lumbar spine. This module may be beneficial to the trainee as it provides useful practice in pattern recognition and probe handling prior to clinical practice.

Funding This project has been funded by the Baxter Corporation Canadian Research Award in Anesthesia.

\section{References}

1. Grau T, Leipold RW, Conradi R, Martin E, Motsch J. Efficacy of ultrasound imaging in obstetric epidural anesthesia. J Clin Anesth 2002; 14: 169-75.
2. Grau T, Leipold RW, Conradi R, Martin E, Motsch J. Ultrasound imaging facilitates localization of the epidural space during combined spinal and epidural anesthesia. Reg Anesth Pain Med 2001; 26: 64-7.

3. National Institute of Health and Clinical Excellence. UltrasoundGuided Regional Nerve Block (IPG285). Available from URL: http://www.nice.org.uk/Guidance/IPG285 (accessed January 2013).

4. Margarido CB, Arzola C, Balki M, Carvalho JC. Anesthesiologists' learning curves for ultrasound assessment of the lumbar spine. Can J Anesth 2010; 56: 120-6.

5. Doyle JD, Webber EM, Sidhu RS. A universal global rating scale for the evaluation of technical skills in the operating room. Am J Surg 2007; 193: 551-5.

6. Chin KJ, Perlas A, Singh $M$, et al. An ultrasound-assisted approach facilitates spinal anesthesia for total joint arthroplasty. Can J Anesth 2009; 56: 643-50.

7. Chin KJ, Chan V. Ultrasonography as a preoperative assessment tool: predicting the feasibility of central neuraxial blockade. Anesth Analg 2010; 110: 252-3.

8. Furness G, Reilly MP, Kuchi S. An evaluation of ultrasound imaging for identification of lumbar intervertebral level. Anaesthesia 2002; 57: 277-80.

9. Margarido CB, Mikhael R, Arzola C, Balki M, Carvalho JC. The intercristal line determined by palpation is not a reliable anatomical landmark for neuraxial anesthesia. Can J Anesth 2011; 58: 262-6.

10. Watson MJ, Evans S, Thorp JM. Could ultrasonography be used by an anaesthetist to identify a specified lumbar interspace before spinal anaesthesia? Br J Anaesth 2003; 90: 509-11.

11. Chueh H, Barnett GO. "Just-in-time" clinical information. Acad Med 1997; 72: 512-7.

12. Brandenburg $D C$, Ellinger $A D$. The future: just-in-time learning expectations and potential implications for human resource development. Advances in Developing Human Resources 2003; 5: 308-20.

13. Park J, MacRae H, Musselman LJ, et al. Randomized controlled trial of virtual reality simulator training: transfer to live patients. Am J Surg 2007; 194: 205-11.

14. Boet $S$, Bould MD, Schaeffer R, et al. Learning fibreoptic intubation with a virtual computer program transfers to "hands on" improvement. Eur J Anaesthesiol 2010; 27: 31-5.

15. Johnson KB, Syroid ND, Drews FA, et al. Part Task and variable priority training in first-year anesthesia resident education: a combined didactic and simulation-based approach to improve management of adverse airway and respiratory events. Anesthesiology 2008; 108: 831-40. 